\title{
Patterns in Illinois educational school data
}

\author{
Cacey S. Stevens, ${ }^{1}$ Michael Marder, ${ }^{2}$ and Sidney R. Nagel ${ }^{1}$ \\ ${ }^{1}$ The James Franck Institute and Department of Physics, The University of Chicago, \\ Chicago, Illinois 60637, USA \\ ${ }^{2}$ Department of Physics, The University of Texas at Austin, Austin, Texas 78712, USA
}

(Received 28 January 2015; published 26 May 2015)

\begin{abstract}
We examine Illinois educational data from standardized exams and analyze primary factors affecting the achievement of public school students. We focus on the simplest possible models: representation of data through visualizations and regressions on single variables. Exam scores are shown to depend on school type, location, and poverty concentration. For most schools in Illinois, student test scores decline linearly with poverty concentration. However, Chicago must be treated separately. Selective schools in Chicago, as well as some traditional and charter schools, deviate from this pattern based on poverty. For any poverty level, Chicago schools perform better than those in the rest of Illinois. Selective programs for gifted students show high performance at each grade level, most notably at the high school level, when compared to other Illinois school types. The case of Chicago charter schools is more complex. Up to 2008, Chicago charter and neighborhood schools had similar performance scores. In the last few years, charter students' scores overtook those of students in traditional schools as the number of charter school locations increased.
\end{abstract}

DOI: 10.1103/PhysRevSTPER.11.010113

PACS numbers: 01.40.- $\mathrm{d}$

\section{INTRODUCTION}

Each year, public school teachers and administrators face the pressure of increasing the number of students who meet academic performance benchmarks. Standardized exams are a primary measure of this achievement. Despite the great differences in support available to different groups of students, all schools are tested by the same statewide standards. There is a large amount of freely available data describing exam results. The Illinois State Board of Education makes aggregate data for all public schools available each year [1]. Unfortunately, the abundance of data is hard to decipher. We use visualization techniques to display and identify patterns in the data.

Our method of analysis is deliberately simple: scatter plots are employed to detect patterns. Our methods are different from multivariate regressions, which are commonly used to study data of this type. We suspect such multivariate regressions make it difficult for the public to understand the data. The statistical methods and results require specialized software and training to interpret. Thus, before data enter public discourse, they typically pass through a study or report in which the complex statistical computations are performed, and their conclusions are deduced for the lay audience. Multivariate regressions are not necessary to extract results in this instance.

Published by the American Physical Society under the terms of the Creative Commons Attribution 3.0 License. Further distribution of this work must maintain attribution to the author(s) and the published article's title, journal citation, and DOI.
Representation by statistical models and analyses is often said to be necessary because raw data provide us with so many numbers that one cannot make sense of them. However, visual images present a way to display a large number of data points simultaneously, making visualization an important part of science, particularly in the study of complex phenomena. Our approach of data visualization provides accessible and persuasive results for education through methods commonly used to uncover patterns in physics. An audience with a training in physics may especially appreciate the approach to studying K-12 educational achievement, while reliance on visual methods can be unfamiliar to other audiences. Therefore, this work should be valuable to physicists engaged in physics education research.

Statistical analysis is often needed to separate true patterns from those due to chance. This is particularly true in settings where the number of data points is small or the scatter is very large. However, in the cases we will examine, the number of data points is so large and the unveiled patterns so clear that elaborate statistical methods are not needed to establish them. The scatter plots have an impact that multivariate regressions lack. We apply simple regression techniques to show that the patterns found visually are statistically meaningful.

We explore connections between exam performance in Illinois schools and various factors, with a particular focus on poverty concentration as represented by a conventional proxy: the percent of students who qualify for lunch at free or reduced price. Poverty concentration of a school is strongly connected with its performance on standardized exams, as has been shown before [2-7]. In general, as 
poverty concentration rises, test scores fall. In most cases, this remains true for charter schools, which have more autonomy than the traditional public schools and have been widely promoted as a way for students to escape unsuccessful local schools.

We consider additional factors aside from poverty: location and selective programs. We also study the performance over time. Poverty concentration influences performance in Chicago schools differently than the rest of the state. Additionally, the state has a number of selective schools, where students are chosen by their test scores. These schools do not exhibit the patterns relating poverty and test performance. The comparisons between selective and open-admissions programs are most striking for high schools. Lastly, there are noticeable changes over time, particularly in the performance of charter high schools.

This paper is organized as follows: Sec. II describes the types of Chicago public schools and the high-stakes exams in Illinois public education. In Sec. III we describe how performance on standardized exams depends on poverty concentration in Chicago compared to the rest of Illinois. The performance of different Chicago school types is also described. The achievement on measures of college readiness is discussed in Sec. IV. In Sec. V, we show how Chicago schools have been changing over time. We conclude in Sec. VI.

\section{PUBLIC EDUCATION IN ILLINOIS}

According to the U. S. Census Bureau, Chicago is by far the largest city in Illinois with about $21 \%$ of the state's 12.8 million residents; the second largest city in Illinois, Aurora, IL, contains only about $1.5 \%$ of the state's residents [8]. The Illinois State Board of Education oversees performance of public education throughout the state and sets prekindergarten to 12 th grade education policies, while local school districts monitor operation of public schools of the area. The Chicago Public School System is the third largest school district in the United States and includes about 660 elementary and secondary schools. Chicago holds $17 \%$ of Illinois public schools and serves about 400000 students [9]. Most Chicago schools are conventional neighborhood programs, but there are also several nontraditional school options. The school types discussed in this article are defined as follows [10]:

Career Academy: Students receive career-focused education and hands-on experience in fields such as health, communications, or manufacturing.

Charter: Independently operated schools open to all Chicago students; students are admitted based on lottery if the number of applicants exceeds the available slots.

Magnet: Places importance on one particular subject area, such as international studies or fine arts; students are typically chosen by lottery after submitting an application.

Military Academy: Students wear uniforms and are taught in a structured environment focused on building team and leadership skills; there are no attendance boundaries for application.

Neighborhood: Traditional programs; students who live within the school's residential boundary do not submit an application to enroll in the school.

Selective Enrollment: Academically advanced programs providing accelerated, college preparatory instruction; enrollment is based on entrance and/or standardized exam scores; they include regional gifted centers housed within neighborhood or magnet schools, where there are two separate programs within the school.

Charter schools receive considerable attention, since they are publicly funded schools that operate without the managing control of the school system [11]. These schools have been in place in Illinois since 1996 with the purpose of using innovative practices, such as longer school days, autonomy to hire teachers, or subject-focused curricula, to better serve at-risk children [12]. As of the 2013-2014 academic year, about 75 percent of Illinois charter schools were in the Chicago Public School system, and these programs served about 49500 students in Chicago [1]. Many charter programs have several locations, and the city has about 130 charter campuses [9]. The growth of charter schools has been promoted in Chicago as an effort to improve the city's education system $[13,14]$. Therefore, in spite of recent education budget cuts and neighborhood school closings [15], new charter schools are steadily opening each year [13]. Accordingly, the performance of charter schools has been the subject of several reports [16-19], whose strongly differing conclusions illustrate the degree to which regression methods alone divide specialists and baffle the public. The goal of this paper is not to argue the effectiveness of any school type. Instead we describe powerful ways to analyze the school's performance on standardized exams and suggest that simpler formal methods aid in reaching consensus.

Standardized exams play an important role in providing the data on which public officials base decisions about educational policy. Starting at 3rd grade, Illinois public school students are required to take standardized exams to evaluate their development during the year. Exams cover subject areas such as mathematics, reading, science, and writing. The Illinois State Board of Education (ISBE) is responsible for forming the assessment each year, and the student, teacher, school, district, and state are all reviewed based, in part, on the exam results. In 2014, Illinois adapted the Common Core State Standards, which assess math and English language skills that students are expected to know after each grade [20].

Scores are reported in terms of score ranges determined by the ISBE, and students are graded with one of the following performance levels: exceed standards, meet standards, below standards, or academic warning [21]. A student passes the exam by meeting or exceeding standards of each subject test. Achievement scores at the school level 
TABLE I. Description of standardized exams from which scores are used for this analysis.

\begin{tabular}{|c|c|c|c|}
\hline Exams & Grades & Description & Scores \\
\hline $\begin{array}{l}\text { Illinois standards } \\
\text { achievement test (ISAT) }\end{array}$ & $3 \mathrm{rd}-8 \mathrm{th}$ & Measures student math achievement each year. & $\begin{array}{l}\text { Performance level assigned } \\
\text { based on a fixed scale. }\end{array}$ \\
\hline $\begin{array}{l}\text { Prairie state achievement } \\
\text { exam (PSAE) }\end{array}$ & 11 th & $\begin{array}{l}\text { Assesses student preparation for postsecondary } \\
\text { education and ability to apply math } \\
\text { skills to the workplace. }\end{array}$ & $\begin{array}{l}\text { Scores range from } 120 \text { to } 200 ; \\
\text { performance level assigned } \\
\text { based on a fixed scale. }\end{array}$ \\
\hline $\mathrm{ACT}$ & 11 th & $\begin{array}{l}\text { Exam commonly used for admissions into } \\
\text { four-year colleges and universities. }\end{array}$ & Scores range from 1 to 36 \\
\hline
\end{tabular}

are expressed as the percent of students in the school who reach each performance level. Standardized exams, such as the ACT [22], are used as a measure of college readiness; there is commonly a minimum required score for scholarships or admission into some selective universities. Up to the 2014 testing season, the ACT was given to Illinois high school juniors as part of the mandatory Prairie State Achievement Exam (PSAE); the ACT will become optional in 2015 [23]. Table I lists information about standardized math exams in Illinois.

Benchmarks are set for the education system each year, and scores must be reported for school, district, and state accountability purposes. Schools are then classified according to success at meeting the targets and may be closed if student performance goals are not met. New educational policies are also implemented to improve students' scores [14]. In April 2014, Illinois joined many other states receiving a waiver from the No Child Left Behind law [24], protecting school districts from penalty if testing benchmarks are not met. This is in exchange for a package of additional reform measures. It is therefore useful to have ways to display how schools have performed and show the effects of such policies. All school-level performance data are available from ISBE, including school programs, performance scores, and demographics. Through data visualization of school scores, we find and interpret patterns among school characteristics.

\section{POVERTY AND SCHOOL PERFORMANCE IN AND OUT OF CHICAGO}

Figure 1(a) displays the performance of 670 Illinois public high schools as a function of poverty concentration. In this case, the measure of school achievement is given as the percentage of students in the school who met or exceeded ISBE standards of the 2013 Mathematics PSAE, an exam given to high school juniors [25,26]. Poverty concentration is defined as the percent of students who received lunches at no or reduced cost based on the maximum family income requirement. This is a standard measure of poverty in schools. For the 2013-2014 academic year, a family of four with an annual household income below $\$ 43,568$ qualified for the free or reduced lunch program [27]. Low-income families choosing not to sign up for the lunch program are not represented. Two additional factors are expressed in this visualization by the color and size of each circle: the percent of minority students (African American and Hispanic) and the number of test takers at each school, respectively. Several schools were excluded from the data either for not completely reporting information or for reporting $0 \%$ of students passing. (Waukegan, IL area schools are not displayed due to a discrepancy in 2013 poverty concentration information.) Data for the PSAE Reading and Science exam scores follow similar patterns as described here. For brevity, only math exam performance is shown in this paper.

Performance is strongly connected with concentration of low-income students, as shown by the significant decline in the percent of students passing with increasing poverty concentration. Within many schools in low-income neighborhoods (those with greater than $80 \%$ poverty concentration), less than $50 \%$ of students pass the exam. There is also a connection with minority concentration; the coloring on the graph shows a strong correlation between poverty concentration and minority concentration. In $2013,65 \%$ of white Illinois students passed the exam compared to only $36 \%$ of Hispanic students and $21 \%$ of African American students [1].

There are many outliers from the overall decline of performance with poverty shown in Fig. 1(a). However, when we remove all schools located in Chicago, as shown in Fig. 1(b), the remainder of the state's schools present a remarkably tight relationship between poverty concentration and passing fraction. For example, there are no schools with more than $80 \%$ poverty concentration and more than $40 \%$ students passing, as there are no schools with less than $20 \%$ poverty concentration and less than $40 \%$ students passing.

When only Chicago schools are considered, we find that the relationship between poverty concentration and passing fraction is possible to break. Figure 2(a) shows the performance of 115 Chicago schools. They clearly do not show the same association with poverty as in Fig. 1(b). Most schools have a poverty concentration greater than $50 \%$, and among these schools we see significant variations in performance. For comparison, Aurora, the second largest city in Illinois, only has four high schools, and these 

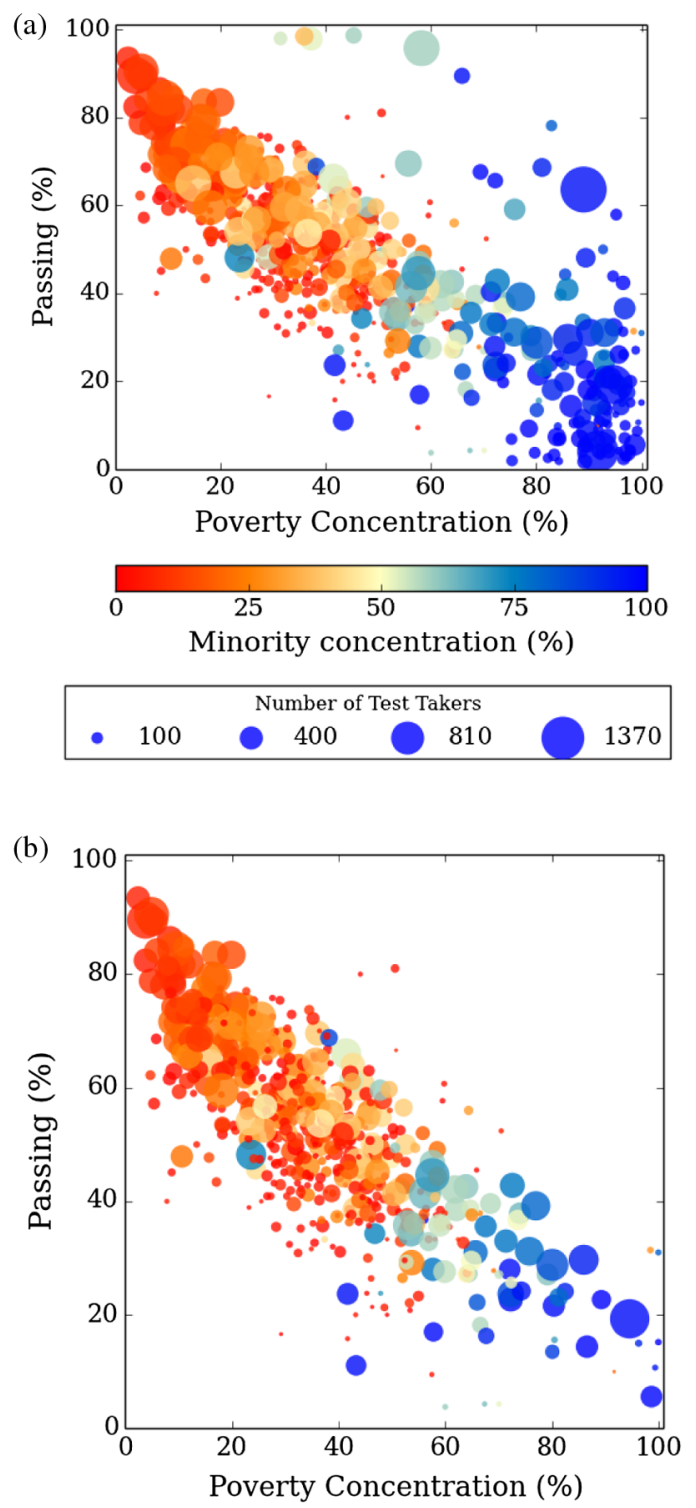

FIG. 1. (a) Percent of 11th graders at each Illinois school who passed the 2013 Math PSAE as a function of poverty concentration. The area of each point represents the number of test takers, and the color represents the percentage of minority students. (b) Same as (a) but excluding Chicago schools. It becomes particularly clear that Illinois school performance is very tightly correlated with poverty concentration and concentration of minority students.

schools all fit well with the trend shown in Fig 1(b). Schools in the areas surrounding Chicago, including Will, Lake, Dupage, and Cook counties, also fit Fig. 1(b) well. Only Chicago is different.

Chicago has several types of programs, as highlighted in Fig. 2(b): career or military, charter, magnet, selective enrollment, and neighborhood. There is a fairly large spread in achievement among neighborhood, career or military, and charter schools, though most have less than $50 \%$ passing. One exception is the Noble Street Charter
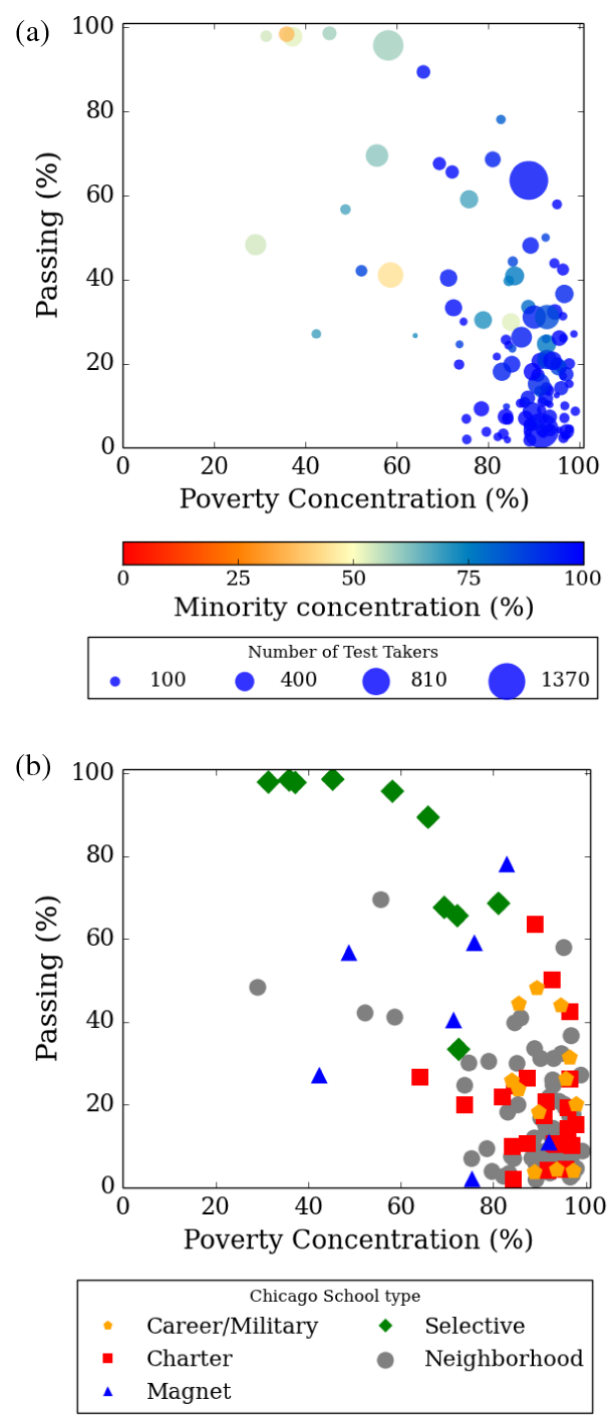

FIG. 2. (a) Percent of 11 th graders at Chicago schools only who passed the 2013 Math PSAE as a function of poverty concentration. The size and color of the points represent the number of test takers and percent of minority students, respectively. (b) Chicago schools are again presented; in this case, symbols indicate the type of school as given in the table.

System where $89 \%$ are considered low income and $63.6 \%$ of the 1585 tested students passed the PSAE. The seven highlighted magnet schools also vary significantly. Von Steuben High School, with 59\% passing at $76 \%$ poverty concentration, and Devry Advantage High, with 78\% passing at $83 \%$ poverty concentration, perform better than anticipated based on the performance-poverty concentration trend. Two magnet programs show surprisingly low performance scores. Administrators of Crane Medical Prep High School, at 2\% passing, attribute this to reporting error, while Clark Academic Prep, which fits the pattern in Fig 1 (b) with $86 \%$ poverty concentration and $10 \%$ passing, is now on probation. As one might expect, the selective enrollment programs, which have competitive admissions 
and accelerated instruction, have results superior to all other Chicago schools, with several having over $90 \%$ of students passing the math PSAE. Regional gifted centers, smaller programs housed within neighborhood or magnet schools, are featured as selective enrollment programs. For instance, Morgan Park High school has an international studies gifted program within the traditional school and is noted in Fig. 2(b) as a selective enrollment program with $37 \%$ passing.

Proceeding to examine lower grades, we find a very similar set of patterns: school performance outside of Chicago clusters tightly around a line where performance declines as poverty rises. Chicago schools show more complex patterns, which depend, in part, on school type. In grades 3 through 8, students' accomplishment is measured through the ISAT, and, as with the PSAE, "passing" is equivalent to meeting or exceeding exam standards. For each grade level, we find the percent of students passing the 2013 exam at Illinois schools, excluding Chicago, as a function of poverty concentration; this is shown in Fig. 3.

Since passing fractions of Illinois schools outside of Chicago clearly show a linear relationship with poverty concentration, we can perform simple regressions to obtain the best-fit line $f_{i}$ to describe these patterns. The quality of the fit is depicted by its standard deviation $\sigma$, the variation of the schools' passing fractions from the best-fit line, as given by

$$
\sigma=\sqrt{\frac{\sum\left[p_{i}-f_{i}\left(c_{i}\right)\right]^{2}}{N}}
$$

where $p_{i}$ is the passing fraction of each school, $f_{i}\left(c_{i}\right)$ is determined from the regression line at $c_{i}$, and $N$ is
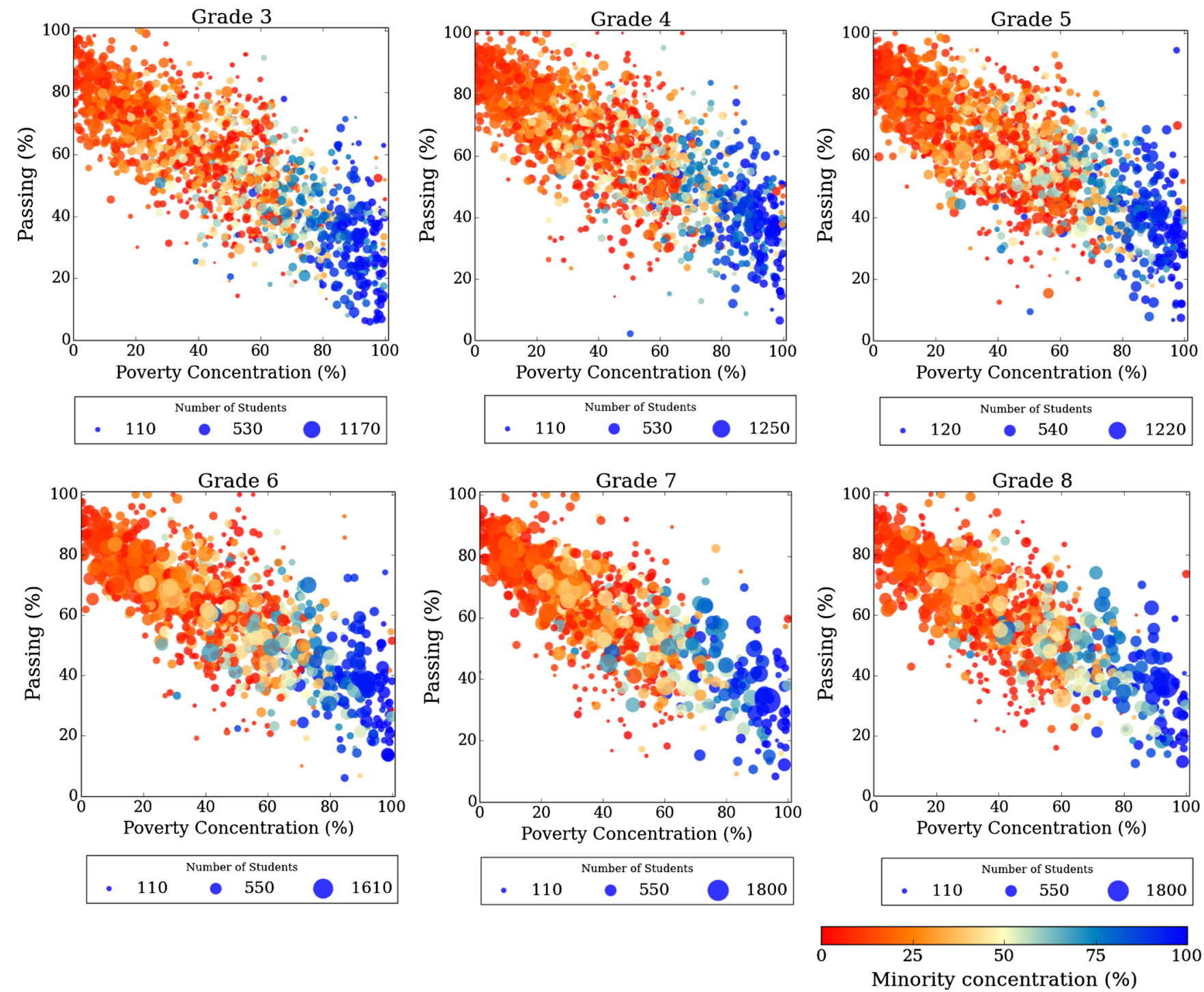

FIG. 3. Illinois school performance, excluding Chicago schools, on the 2013 Math ISAT at grades 3 through 8 . The area of each point represents the total number of students tested at each school, and the color represents the percentage of minority students in the school. Performance declines with increasing poverty concentration. 
TABLE II. Regression lines for passing fraction $p_{i}$ versus poverty concentration $c_{i}$ plots of each grade level [Figs. 1(b) and 3], and the respective standard deviations $\sigma$. Data are for 2013 mathematics exams and apply to Illinois schools outside of Chicago. Regression lines are used to compare Chicago school programs to non-Chicago schools, as shown in Fig. 4(b).

\begin{tabular}{llc}
\hline \hline Grade & Regression line & $\sigma$ \\
\hline 3 & $f=-0.56 c_{i}+83.7$ & 11.9 \\
4 & $f=-0.51 c_{i}+86.0$ & 12.2 \\
5 & $f=-0.52 c_{i}+85.2$ & 12.4 \\
6 & $f=-0.53 c_{i}+85.5$ & 12.5 \\
7 & $f=-0.54 c_{i}+82.9$ & 12.1 \\
8 & $f=-0.54 c_{i}+82.5$ & 12.1 \\
11 & $f=-0.67 c_{i}+76.5$ & 10.6 \\
\hline \hline
\end{tabular}

the number of schools. The regression line equations and their corresponding $\sigma$ are given in Table II. The simple regressions show the consistency of the relationship between poverty and performance among different grades.

We continue to a comparison of performance at schools in and out of Chicago. Figure 4(a) gives examples of how Chicago area schools, excluding selective enrollment programs, perform at 8th and 11th grades compared to those of the rest of the state. The solid line indicates the best-fit line for each set of data, and the shaded region displays the $68 \%$ confidence interval corresponding to one standard uncertainty around the best-fit line. At grade 8, many of the Chicago schools (shown in blue) earned higher scores than the average of non-Chicago programs (shown in red), though there is a large spread among Chicago schools. Similar patterns appear at 3rd to 7 th grades. However, for 11th grade scores, the difference between Chicago and other Illinois schools is not as significant over the full range of poverty concentration. The performance of Chicago high schools is best examined by considering programs in which at least $48 \%$ of students are identified as low income, a criterion that applies to 103 of the 105 career, charter, neighborhood, magnet, and military schools represented. Since data for less than $48 \%$ poverty concentration are so sparse in Chicago, we discard this range from the comparison. When restricting attention to the range of $48 \%-$ $100 \%$ poverty concentration, we find that Chicago high schools have significantly higher scores than schools in the rest of Illinois, except for the highest poverty schools where the difference vanishes on average.

Figure 4(b) shows how much each type of school in Chicago deviates from the fit for the rest of the state (dashed line) at 3rd through 8th grades and for 11th grade. Career and military schools are excluded. For 11th grade, only schools with poverty concentration higher than $48 \%$ are considered. We define $\Delta_{i}$ for a school $i$ to be the difference between the actual passing fraction $p_{i}$ and the fraction $f_{i}$ we would anticipate based upon the best fit line
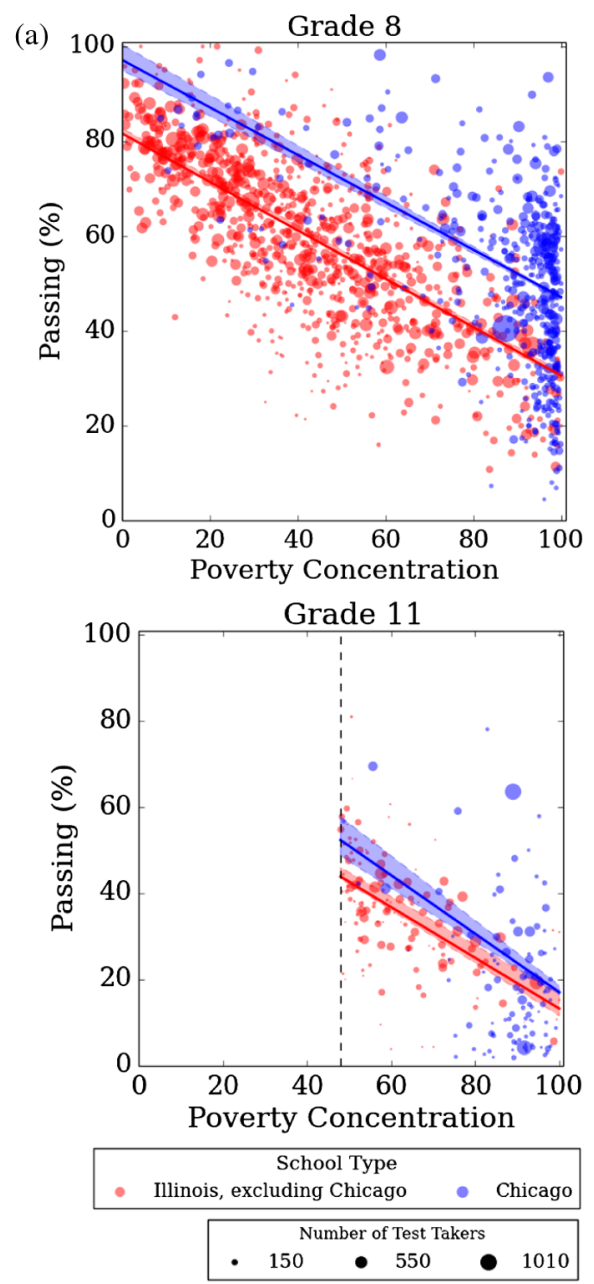

(b)

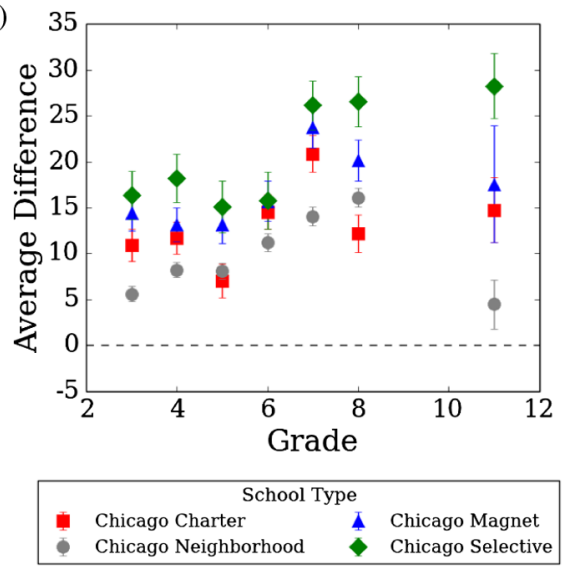

FIG. 4. (a) Math performance scores of Chicago schools (blue) are compared to the fit to the data of other Illinois schools (red) at 8th and 11th grades. (b) Average differences of 2013 math exam performance at Chicago school programs when compared to other Illinois schools. The average difference $\Delta$ of each school category is determined by $\Sigma N_{i}\left[p_{i}-f_{i}\left(c_{i}\right)\right] / \Sigma N_{i}$, where $p_{i}$ is the percent passing at each school, $f_{i}$ is the expected performance at that grade level (given in Table II) based on the poverty concentration $c_{i}$ of the school, and $N_{i}$ is the number of students in each school of that category. The bars represent standard uncertainty. Table III gives the number of schools represented. 
of Illinois schools (excluding Chicago) appropriate for that grade (Table II) at poverty concentration $c_{i}$. The value of $\Delta_{i}$, is positive (negative) if the school performs better (worse) than expected for other Illinois programs. The average difference is weighted by the number of test takers at each school. For example, the average difference of Chicago magnet schools is given by

$$
\frac{\sum_{i \in \text { magnet }}\left(\Delta_{i} N_{i}\right)}{\sum_{i \in \text { magnet }} N_{i}},
$$

where $N_{i}$ is the number of students in each school and the total number of schools is given in Table III.

At every grade level, all Chicago school types, including neighborhood schools, perform better, on average, than expected based on achievement of the rest of the state. Neighborhood schools have increasingly better performance up to grade 8. At 11th grade, Chicago's neighborhood programs score slightly above the rest of the state though less pronounced than at lower grades. Additionally, charter school systems perform below other Chicago schools at grades 5 and 8, and magnet programs lie consistently above charter and neighborhood schools. Selective enrollment schools, not surprisingly, have the highest performance at all grades. This is especially striking at 11th grade where selective enrollment programs show a significant jump, while neighborhood schools decline. In high school, most gifted programs are full-site centers, meaning that all students follow the more rigorous curriculum. In contrast, ten of the elementary level selective enrollment programs are regional gifted centers. High school students in selective programs must also have demonstrated high scores on previous standardized exams (ISAT). On the other hand, elementary students are admitted based on a school's entrance exam and not necessarily performance on standardized state exams. This likely contributes to the increased difference at 11th grade compared to lower grades in gifted programs.

TABLE III. Number of schools represented by each point of Fig. 4(b).

\begin{tabular}{lccccc}
\hline \hline Grade & Charter & Magnet & Selective & Neighborhood & Illinois \\
\hline 3 & 21 & 35 & 14 & 427 & 1685 \\
4 & 21 & 36 & 14 & 422 & 1654 \\
5 & 24 & 36 & 14 & 421 & 1571 \\
6 & 23 & 37 & 14 & 405 & 1107 \\
7 & 24 & 38 & 17 & 390 & 913 \\
8 & 22 & 37 & 18 & 389 & 911 \\
$11^{\text {a }}$ & 22 & 6 & 6 & 63 & 129 \\
\hline \hline
\end{tabular}

${ }^{\mathrm{a}}$ At grade 11 , only schools with more than $48 \%$ concentration of low-income students are considered.

\section{MEASURE OF COLLEGE READINESS}

The ACT measures college readiness at high schools. Accordingly, we note whether, on average, students of Illinois schools are attaining satisfactory ACT scores. Up to the 2014-2015 academic year, Illinois 11th graders took the ACT for free as part of the mandatory state administered exams offered to public school students [23]. Therefore, the ACT is the key exam for college admissions, as opposed to the SAT.

Figure 5(a) shows the average math ACT score of each Illinois high school as a function of poverty concentration. As with other state standardized exams, ACT math performance declines with increasing concentration of lowincome students. This is in agreement with a study of Dixon-Roman et. al. indicating a correlation between parental income and student's performance on college readiness exams [28]. Most schools with less than 20\% poverty concentration have an average score above 20 , while, among schools with more than $80 \%$ poverty concentration, few have an average score above 20. The

(a)

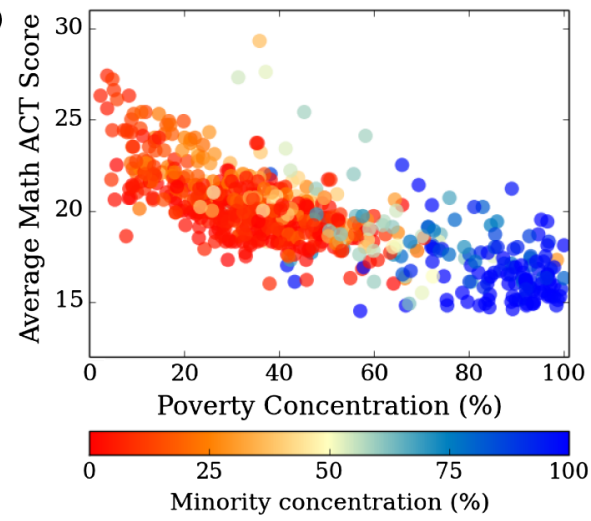

(b)

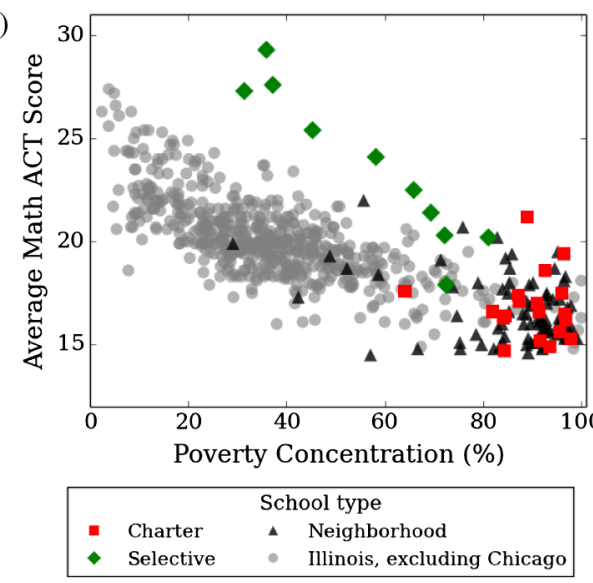

FIG. 5. Average math ACT score of each Illinois school. (a) Math ACT score as a function of poverty concentration. The color of the points indicates the percent of minority students at each school. (b) School types are highlighted: Chicago charter schools, selective enrollment schools in Chicago, neighborhood schools in Chicago, and the rest of Illinois. 
influence of poverty on college admissions exam scores is not unique to Illinois schools. For other states that have been examined, poverty is also connected to school performance in mathematics [6]. Similarly, performance declines with increased concentration of minority students.

We study how Chicago schools possibly diverge from this trend, as seen with scores of the PSAE and ISAT. In Fig. 5(b), we highlight schools located in Chicago. The symbols represent the different types of programs: Chicago charter, Chicago selective enrollment, Chicago neighborhood, or Illinois, excluding Chicago. All Chicago neighborhood schools cluster at average scores of about 15 to 20, and there is no significant trend with poverty among neighborhood schools. The best performing schools are all selective enrollment, college preparatory schools in Chicago, although performance in these schools does decline with poverty. The decline displayed by selective schools, which is unlike that of PSAE performance [Fig 2(b)], may reflect the effect of students being chosen by performance on the state exams, not the ACT. With an average score of 17.9, Morgan Park High, a regional gifted center, is the lowest among gifted programs.

Previous analyses show that attending a Chicago charter high school may have positive effects on ACT scores [17]. It is often argued that charter schools improve student achievement due to innovative methods of instruction and discipline to prepare students for college. However, our present study indicates that scores of most charter schools cluster around similar scores to neighborhood schools at the same poverty level, as was also noted in a recent report [19]. There is an exception: the Noble Street Charter System with an average score of 21.2. Note that ISBE reports only one score for all campuses of a charter school system, such as Noble Street Charters. According to a separate performance report from the Chicago Public School System, the average scores on the 2013 Math ACT among Noble Street schools ranged from 19.2 at the Rowe-Clark campus to 23.7 at the UIC campus [29].

\section{SCHOOL PERFORMANCE OVER TIME}

Thus far we have only considered school performance in 2013, comparing various types of educational programs at each grade level. In this section we address the evolution of these results over time. For example, the number of charter schools in Chicago has grown consistently as new schools and locations open. Accordingly, we ask if there has been an overall improvement of the charter school system as it grew. Figure 6 shows the total percent of 11th grade students in Chicago charter and neighborhood high schools (excluding selective enrollment, magnet, career, and military schools) and non-Chicago schools who passed the math PSAE each year. The numbers of schools and students represented are given in the table of Fig. 6. The percent of students passing is obtained by the fraction of the sum of all students in each charter or high school who met or

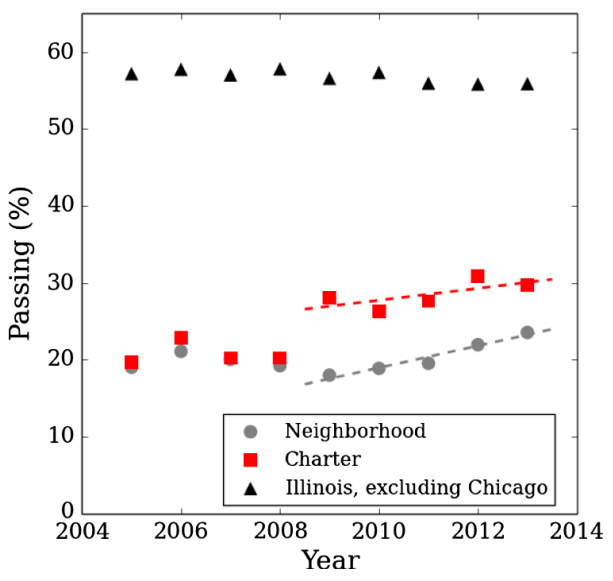

\begin{tabular}{|c|c|c|c|c|c|c|c|c|c|}
\hline & 2005 & 2006 & 2007 & 2008 & 2009 & 2010 & 2011 & 2012 & 2013 \\
\hline \hline & \multicolumn{10}{|c|}{ Number of School Systems } \\
\hline Charter & 7 & 8 & 9 & 11 & 13 & 14 & 15 & 18 & 22 \\
Neigh. & 53 & 58 & 58 & 67 & 62 & 65 & 67 & 64 & 64 \\
IL & 549 & 544 & 550 & 550 & 551 & 552 & 553 & 555 & 555 \\
\hline \multicolumn{8}{|c|}{ Number of Students Tested } \\
\hline Charter & 735 & 882 & 1026 & 1131 & 1869 & 2489 & 3926 & 4688 & 5305 \\
Neigh. & 11287 & 11140 & 11807 & 14099 & 13640 & 12832 & 14452 & 13987 & 13297 \\
IL & 105808 & 106149 & 110103 & 111504 & 110483 & 110663 & 118988 & 118397 & 115858 \\
\hline
\end{tabular}

FIG. 6. Percent of Chicago charter and traditional high school students and other Illinois school students who passed the math PSAE each year. There was a performance shift in 2009 among Chicago students after which a greater percent of charter students passed. Neighborhood schools have improved at about $1.5 \%$ per year from 2009 to 2013 , compared to $0.8 \%$ per year among charter schools, as determined from the slopes of each fit. The table gives the number of schools and the number of students tested each year in those schools.

exceeded exam standards to the total number of students tested in those schools each year:

$$
\frac{\sum_{i \in \text { school }}\left(p_{i} \times N_{i}\right)}{\sum_{i \in \text { school }} N_{i}},
$$

where $p_{i}$ is the percent passing and $N_{i}$ is the number of students tested at each school of the program type (non-Chicago, Chicago charter, or Chicago traditional) in each year. The concentration of low-income students is not considered in this comparison.

The percentage of students passing remained at only about $18 \%$ to $33 \%$ at Chicago neighborhood and charter programs from 2005 to 2013, compared to about 55\% of Illinois school students of other communities (due to the lower concentration of low-income students). Up to 2008, charter schools consistently performed at the same level as other high schools in the percent of students passing the exam. However, in the last several years, there has been a shift in performance; between $25 \%$ and $30 \%$ of charter students passed the exam each year since 2009. Charter school scores have increased by about $0.8 \%$ per year from 2009 to 2013. Although neighborhood high schools in Chicago have improved by about $1.5 \%$ each year, the traditional programs have not yet reached the performance of charter schools. 
Some charter programs have been criticized for their high attrition rates [30]; charters expel poorly performing students at a higher rate than at other public schools, resulting in a boost in test scores. Chicago Public Schools recently released data that support the claim [31]. The expulsion rates of 2012-2013 at Chicago charters was $0.61 \%$ compared to only $0.05 \%$ at traditional schools. Some charter programs noted for high academic performance have expelled $1.5 \%-4.8 \%$ of the student body during the year [29]. Here we provide a rough estimate of the impact of high expulsion rates on math PSAE performance: We assume the extreme case where all expelled students would not have passed the exam and were thereby transferred to a neighborhood school. If those students were not expelled and were instead tested in a charter program, the resulting percent passing in 2013 among charter students would have been $29 \%$ and would have increased among neighborhood students to $24 \%$. Thus, the higher scores of charter programs are not fully explained by their higher expulsion rates.

The number of charter systems has increased in the last nine years from 7 in 2005 to 22 in 2013, not including new campuses of established systems; there were 54 charter high school campuses as of the 2012 academic year. Note that charter systems with several locations may report scores and demographics as one school. In 2008-2009, the number of charter school 11th graders grew by $65 \%$, while some traditional public schools were closed or relocated as part of the renaissance plan of Chicago Public Schools [14]. This must have contributed to the shift apparent in 2009. Even if charter schools pulled stronger students away from neighborhood schools after 2009, the data in Fig. 4(b) indicate the net result for Chicago has been positive. When considering the scores of each charter school separately, we find that most schools do not have a major change in the percent of students passing the exam over several years. Schools that start with strong scores typically remain at the same level, and schools with lower scores do not usually improve. Over the last five years, there have been new charter programs opening, and some of the schools have better performance scores within the first year than established traditional high schools. Accordingly, the overall achievement of charter schools on the 11th grade math exam has been above that of neighborhood schools.

\section{CONCLUSIONS}

We have analyzed standardized exam performance at Illinois schools from 2005 to 2013, making use of public data that anyone can access. Through data visualization methods commonly used in physics, we reveal clear patterns in Illinois education. We have shown that performance at all schools outside of Chicago depends very consistently upon poverty concentration. Outside Chicago, no schools in Illinois with a high concentration of lowincome students have performance scores as great as schools in better-off communities with a poverty concentration less than 20\%. In Chicago, the story is more complicated. Schools in the city have higher scores, on average, than the rest of the state at each grade and poverty level. Performance of Chicago schools depends, in part, on the type of program, such as programs for gifted students and networks of charter schools. Selective enrollment programs consistently have the highest exam achievement compared to other public schools. This is especially true at 11 th grade. These programs also excel in measures of college readiness, such as the ACT, though scores are shown to decline with poverty concentration in this case. In 2013, neighborhood schools performed better than charter schools in grades 5 and 8, and neighborhood and charter high schools have earned similar ranges of performance scores on the ACT. While schools in the rest of Illinois displayed a largely static and discouraging dependence of test performance on poverty, Chicago has improved over the nine year period we examined. In 2009, charter high schools had a shift in scores from about $20 \%$ to $30 \%$ passing math exams, while traditional schools have gradually improved since 2009 .

The overall picture is one in which change in Chicago schooling has produced improvement in test scores for students at all levels of poverty and in all types of schools. Meanwhile, in the rest of the state, the dependence of scores on poverty is stronger and is not changing. This implies that there are several factors associated with poverty that affect student outcomes, and some schools in Chicago have slowly been improving in addressing them. In one analysis, five school-level factors were attributed to low-income, highperforming schools [32]: support for students needs, use of hard data, accountability, relationships with students', and an enrichment mind set. These or similar qualities may be found more strongly among the successful Chicago programs and explain their better performance. In particular, the pressure of competition between schools of different types may have led all of them to improvement even in the presence of concentrated poverty. However, such a conclusion lies outside the scope of purely quantitative methods and would require more qualitative examination of interactions of students, teachers, and communities with schools.

\section{ACKNOWLEDGMENTS}

We are grateful to Thomas Caswell, Leo Kadanoff, and Andrzej Latka for helpful discussions. C. S. acknowledges support from the NSF Graduate Research Fellowship Program. 
[1] Illinois State Board of Education Report, http://www.isbe .net/assessment/report_card.htm.

[2] L. Lippman, S. Burns, and E. McArthur, Urban Schools: The Challenge of Location and Poverty (U.S. Department of Education, National Center for Education Statistics, Washington, DC, 1996).

[3] S. R. Sirin, Socioeconomic Status and Academic Achievement: A Meta-Analytic Review of Research, Rev. Educ. Res. 75, 417 (2005).

[4] M. Marder and D. Bansal, Flow and diffusion of highstakes test scores, Proc. Natl. Acad. Sci. U.S.A. 106, 17267 (2009).

[5] M. Lacour and L. D. Tissington, The Effects of Poverty on Academic Achievement, Educ. Res. Rev. 6, 522 (2011).

[6] M. Marder, Failure of US public secondary schools in mathematics, AASA J. Scholarship Practice 9, 8 (2012).

[7] A. Bendinelli and M. Marder, Visualization of longitudinal student data, Phys. Rev. ST Phys. Educ. Res., 8, 020119 (2012).

[8] U. S. Census Bureau: State and County Quickfacts, http:// www.illinois.gov/census/Pages/default.aspx.

[9] Chicago Public Schools: Stats and Facts, http://www.cps .edu/About_CPS/At-a-glance/Pages/Stats_and_facts.aspx.

[10] Chicago Public Schools: School descriptions, http://cps .edu/schools/Pages/Schools.aspx.

[11] G. Chen, What is a Charter School? (Public School Review, New York, NY, 2015), http://www .publicschoolreview.com/blog/what-is-a-charter-school.

[12] Illinois Charter School Annual Report, Illinois State Board of Education (2005), http://www.isbe.state.il.us/charter/ pdf/charter_annual_05.pdf.

[13] N. Ahmed-Ullah, CPS votes to open 7 more charter schools (Chicago Tribune, Chicago, 2014), http://goo.gl/ LLMtEZ.

[14] Renaissance 2010, http://www.cps.edu/PROGRAMS/ DISTRICTINITIATIVES/Pages/Renaissance2010.aspx.

[15] N. Ahmed-Ullah, J. Chase, and B. Secter, CPS approves largest school closure in Chicago's history (Chicago Tribune, Chicago, 2013), http://goo.gl/SZ6xvq.

[16] Charter schools in Chicago: No Model for Education Reform (Institute of Metropolitan Opportunity at University of Minnesota Law School, 2014), http://goo .gl/zLLsP9.
[17] K. Booker, B. Gill, R. Zimmer, and T. R. Sass, Technical Report, RAND Corporation (2009), http://goo.gl/mpbfJ0.

[18] Debunking Myths About Charter Schools, http://www .pcachicago.org/debunking-myths-aboutcharter- schools/.

[19] D. Mihalopoulos and D. Little, A push for charter schools, but little difference in test scores (Chicago Sun Times, Chicago, 2014), http://politics.suntimes.com/article/ chicago/push-charter-schools-little-difference-test-scores/ mon-04072014-422am.

[20] Common Core State Standards, http://www.isbe.net/ common_core/pdf/ccs_faq.pdf.

[21] ISBE Performance Definitions, http://www.isbe.state.il.us/ assessment/htmls/per_def.htm.

[22] ACT, http://www.act.org/products/k-12-act-test/.

[23] D. Rado, ACT edged out as state brings in new high school exams (Chicago Tribune, Chicago, 2014), http:// www.chicagotribune.com/news/ct-act-optional-2015-met20140722-story.html\#page $=1$.

[24] No Child Left Behind in Illinois, http://www.isbe.net/nclb/.

[25] S. M. Ponisciak, Understanding the Prairie State Achievement Exam, Consortium on Chicago School Research at the University of Chicago 4 (2005), http://ccsr.uchicago .edu/sites/default/files/publications/psae_report.pdf.

[26] Prairie State Achievement Examination, http://www.isbe .net/assessment/psae.htm.

[27] Illinois School Breakfast and Lunch Program, http://www .benefits.gov/benefits/benefit-details/1963.

[28] E. J. Dixon-Roman, H. T. Everson, and J. J. McArdle, Race, Poverty and SAT Scores: Modeling the Influences of Family Income on Black and White High School Students SAT Performance, Teachers Coll. Rec. 115 (2013).

[29] Chicago Public Schools: School Data, http://www.cps.edu/ SchoolData/Pages/SchoolData.aspx.

[30] L. Jurkowitz, Discipline Data: Charters vs. Noncharters, Educ. Week 32, n. 31 (2013), http://www.edweek.org/ew/ section/infographics/charter-disciplineinfographic. html.

[31] N. S. Ahmed-Ullah and A. Richards, CPS: Expulsion rate higher at charter schools (Chicago Tribune, Chicago, 2014), http://goo.gl/HGVlvU.

[32] E. Jensen, Teaching with poverty in mind: What being poor does to kids' brains and what schools can do about it (ASCD, Alexandria, 2009), http://www.ascd .org/publications/books/109074.aspx. 